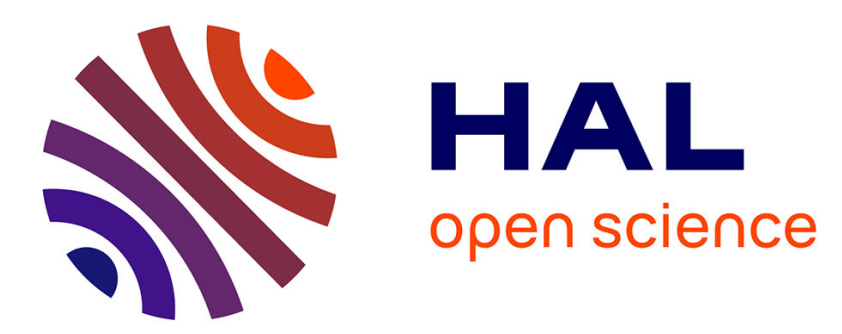

\title{
Improving PDL Tolerance of Long-Haul PDM-OFDM Systems Using Polarization-Time Coding
}

Elie Awwad, Yves Jaouën, Ghaya Rekaya-Ben Othman

\section{To cite this version:}

Elie Awwad, Yves Jaouën, Ghaya Rekaya-Ben Othman. Improving PDL Tolerance of Long-Haul PDMOFDM Systems Using Polarization-Time Coding. Signal Processing in Photonic Communications 2012, Jun 2012, Colorado Springs, United States. SpTu2A. hal-00755779

\section{HAL Id: hal-00755779 \\ https://hal.science/hal-00755779}

Submitted on 22 Nov 2012

HAL is a multi-disciplinary open access archive for the deposit and dissemination of scientific research documents, whether they are published or not. The documents may come from teaching and research institutions in France or abroad, or from public or private research centers.
L'archive ouverte pluridisciplinaire HAL, est destinée au dépôt et à la diffusion de documents scientifiques de niveau recherche, publiés ou non, émanant des établissements d'enseignement et de recherche français ou étrangers, des laboratoires publics ou privés. 


\title{
Improving PDL Tolerance of Long-Haul PDM-OFDM Systems Using Polarization-Time Coding
}

\author{
E. Awwad, Y. Jaouën, G. Rekaya-Ben Othman \\ Institut Télécom / Télécom ParisTech, CNRS UMR5141, 46 rue Barrault 75634 Paris, France \\ E-mail: \{awwad, jaouen, rekaya\}@telecom-paristech.fr
}

\begin{abstract}
We show that Polarization-Time codes can mitigate PDL impairments in long-haul OFDM systems. Coding gains are maintained in weakly non-linear regime and no extra penalty is added when non-linear effects become severe.

OCIS codes: (060.2330) Fiber optics communications, (060.4080) Modulation
\end{abstract}

\section{Introduction}

Polarization Division Multiplexed (PDM) coherent systems are currently the most investigated solutions for long-haul optical fiber transmissions because of the high achieved spectral efficiency. First real-time PDMQPSK systems have been reported at $100 \mathrm{~Gb} / \mathrm{s}$. Orthogonal Frequency Division Multiplexing (OFDM) is presented as an alternative solution to single-carrier QPSK formats [1]. OFDM eliminates all the interference due to dispersive effects: Chromatic Dispersion (CD) and Polarization Mode Dispersion (PMD), with the use of a guard interval, known as cyclic prefix. By sending and receiving data on two orthogonal polarizations, we can represent PDM-OFDM systems as 2x2 Multi-Input-Multi-Output (MIMO) channels. Hence, Space-Time (ST) coding can be easily applied to mitigate Polarization Dependent Loss (PDL) [2]. Unlike CD and PMD, PDL is a non-unitary distortion and cannot be efficiently mitigated by the same digital equalization techniques.

In this paper, we present the performance of a Polarization-Time (PT) coded PDM-OFDM system, taking into account linear and non-linear transmission effects. The results show that non-linear effects induce no extra penalty when PT coding is used, compared to the uncoded case. The Q-penalties of the Golden-, Silver- and uncoded schemes have been investigated for various PDL values.

\section{Optical Channel Model}

A dual-polarization optical fiber transmission system can be described by the following equation where $A_{x}$ (resp. $A_{y}$ ) is the complex envelope of the electrical field on the $x$ (resp. $y$ ) polarization [3]:

$$
\frac{\partial A_{x / y}}{\partial z}=-\frac{\alpha}{2} A_{x / y}-\beta_{1 x / y} \frac{\partial A_{x / y}}{\partial t}-\frac{i \beta_{2}}{2} \frac{\partial^{2} A_{x / y}}{\partial t^{2}}+i \gamma_{N L}\left(\left|A_{x / y}\right|^{2}+\frac{2}{3}\left|A_{y / x}\right|^{2}\right) A_{x / y}
$$

where $\alpha$ is the transmission loss, $\beta_{1 x / y}$ is the group velocity of $x$ (resp. $y$ ) polarization, $\beta_{2}$ the CD parameter and $\gamma_{N L}$ the optical Kerr non-linearity coefficient. Due to linear birefringence, group velocities $\beta_{1 x}$ and $\beta_{1 y}$ are different resulting in PMD effect. The fiber link consists of 20x100km-fiber spans without in-line dispersion compensation. Each span is followed by an optical amplifier that adds ASE noise modeled as white Gaussian.

Besides optical fiber impairments, in-line components such as connectors, amplifiers, etc. introduce a random fading effect known as PDL. Different PDL models exist in literature where only PDL is taken into account [4]. We will use a simple model given by the following matrix:

$$
H_{P D L}=R_{\alpha} \cdot\left(\begin{array}{cc}
\sqrt{1-\gamma} & 0 \\
0 & \sqrt{1+\gamma}
\end{array}\right) \cdot R_{\beta}
$$

where $R_{\alpha}$ and $R_{\beta}$ are two random rotation matrices with uniform distributions in $[0,2 \pi]$, and $\gamma$ is related to the total PDL of the link $\Gamma_{d B}\left(\Gamma_{d B}=10 . \log _{10} \frac{1+\gamma}{1-\gamma}\right)$. We consider constant $\Gamma_{d B}$ values in the range of 0 to $6 \mathrm{~dB}$.

Space-Time coding or more appropriately PT coding in our context, was proven to be theoretically [2] and experimentally [5] effective in mitigating PDL. The performance of the Golden code and the Silver code, the two best codes for $2 \times 2$ MIMO Rayleigh fading channel, was investigated. The principle of PT coding is to transmit linear combinations of data symbols on different polarizations and different channel uses. However, the mentioned works were limited to a linear channel model with additive white Gaussian noise. In our case, we consider a complete OFDM system along with linear and non-linear fiber effects. Still, since no common in-line distributed PDL model exists in literature, we proposed to carry on with a local PDL model. A 40Gb/s PDMOFDM transmission was simulated and the used simulation parameters are summarized in Table 1. 
Table 1 - Simulation parameters related to the channel on the left and to the modulation format on the right

\begin{tabular}{|c|c|c|c|}
\hline Transmission Loss & $0.2 \mathrm{~dB} / \mathrm{km}$ & Total bit-rate & $40 \mathrm{~Gb} / \mathrm{s}$ \\
\hline Chromatic Dispersion & $17 \mathrm{ps} / \mathrm{nm} / \mathrm{km}$ & OFDM subcarriers & 256 \\
\hline Average PMD & $1 \mathrm{ps} / \sqrt{\mathrm{km}}$ & Cyclic prefix & 38 samples \\
\hline$\Gamma_{d B}$ & $0-6 \mathrm{~dB}$ & OFDM symbol duration & $25.7 \mathrm{~ns}$ \\
\hline$\gamma_{N L}$ & $1.5 \mathrm{~km}^{-1} W^{-1}$ & Training sequence & 32 OFDM Symbols \\
\hline
\end{tabular}

Before each 500 data OFDM symbols, we send a 32 symbols long training sequence to estimate the channel as in [6]. At the receiver, we start with cyclic prefix removal and OFDM demultiplexing. Then, channel coefficients are estimated and Maximum Likelihood (ML) decoding of the received data symbols is performed. Finally, bit error rates (BER) are computed.

\section{Simulation Results}

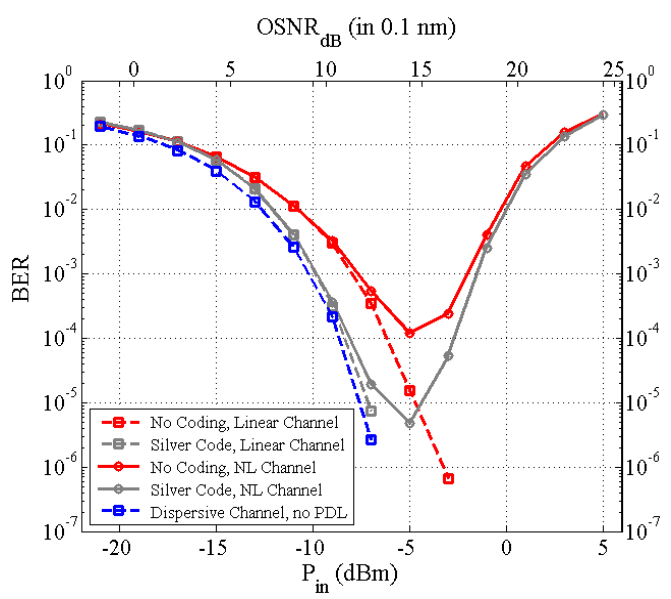

Fig.1 - BER evolution of Silver-coded and un-coded scenarios versus launched power after $2000 \mathrm{~km}(\mathrm{PDL}=6 \mathrm{~dB})$

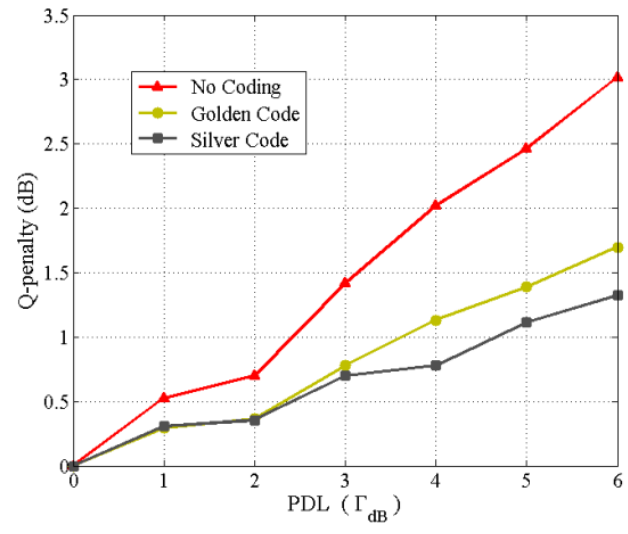

Fig.2 - Q-penalty induced by PDL after $2000 \mathrm{~km}$ (with regard to an uncoded scheme with PDL $=0 \mathrm{~dB}$ ).

In Fig.1, we compare the performance of the Silver-code to the uncoded scheme in the case of a linear and nonlinear channel for a PDL of $6 \mathrm{~dB}$. When non-linearity is considered, BER curves are bell-shaped and we can distinguish 3 regimes: a weak, a medium and a severe non-linear regime. Below a certain input power threshold $(-7 \mathrm{dBm})$, the obtained performance perfectly matches the curve of the linear model. Then, if we increase the input power until $-3 \mathrm{dBm}$, we observe a transient behavior of the curves where a minimum BER is reached. Beyond, we enter a severe non-linear regime where BERs are totally deteriorated for both schemes. By comparing the coded and uncoded cases, we clearly see the efficiency of the Silver code in mitigating PDL. A $2.2 \mathrm{~dB}$ coding gain is observed at $\mathrm{BER}=10^{-3}$. This value match the obtained gain in [2] and [5]. Furthermore, at an input power of $-5 \mathrm{dBm}$, corresponding to a total OSNR of $14 \mathrm{~dB}$, an optimal BER of $5.10^{-6}$ is achieved with the Silver code. Hence, PT coding do not add any extra penalty in presence of non-linear effects. In Fig.2, we show the Q-penalties at the optimal BER for the Golden-, Silver- and un-coded schemes for different PDL values. Optimal BER are converted to Q-values and penalties are computed with regard to an uncoded scheme and a PDL-free link. We notice that penalties are smaller when PT coding is used. A 3dB Q-penalty is obtained without coding for $\mathrm{PDL}=6 \mathrm{~dB}$, whereas the penalty is only $1.3 \mathrm{~dB}$ with the Silver code.

\section{Conclusion}

In this paper, we have tested the performance of PT coding in a complete PDM-OFDM transmission system. We have seen that this format resists to non-linear effects for normally used input power values. Further investigation of these results is required through the use of a distributed PDL model in order to take in account any interaction of PDL with ASE noise and non-linear effects.

\section{References}

[1] W. Shieh et al., "Theoretical and experimental study on PMD-supported transmission using polarization diversity in coherent optical OFDM systems", Opt. Express 15, pp. 9936-9947, 2007.

[2] S. Mumtaz et al., "Space-Time codes for optical fiber communication with polarization multiplexing", ICC'10, paper ON2p, 2010

[3] G. Agrawal, "Non-Linear Fiber Optics", (Academic Press, Fourth Edition), Chap.6, 2007.

[4] A. Mecozzi et al., "The Statistics of PDL in Optical Communication Systems", Photon. Technol. Lett., PTL-14, pp. 313-315, Mar. 2002.

[5] S. Mumtaz et al., "Experimental Demonstration of PDL Mitigation Using Polarization-Time Coding in PDM-OFDM Systems", SPPCOM'11, SPWB6, 2011. [6] S.L. Jansen et al., "121.9-Gb/s PDM-OFDM Transmission with 2-b/s/Hz Spectral Efficiency Over 1000 km of SSMF", J. Lightwave Technology 27, pp. $177-188,2009$. 